QUARTERLY OF APPLIED MATHEMATICS

VOLUME LXIII, NUMBER 4

DECEMBER 2005, PAGES 791-792

S 0033-569X(05)00991-1

Article electronically published on October 6, 2005

\title{
ON SUMS OF CONSECUTIVE INTEGERS
}

\author{
BY \\ MICHAEL J. C. BRITT (The Montessori School, East Providence, RI 02914), \\ LILLIE FRADIN (The Montessori School, East Providence, RI 02914), \\ KATHY PHILIPS (The Montessori School, East Providence, RI 02914), \\ DIMA FELDMAN (Department of Physics, Brown University, Providence, RI 02906), \\ AND \\ LEON N COOPER (Department of Physics, Brown University, Providence, RI 02906)
}

Abstract. We prove the conjectures of Michael Britt and Lillie Fradin concerning sums of consecutive integers.

Let $n+(n+1)+\ldots+(n+j)=\frac{(j+1)(2 n+j)}{2} \equiv(n, j) ; n \geq 1, j \geq 1$.

Conjecture I. $(n, j)$ does not contain numbers of the form $2^{N}$.

Proof. $2^{N}$ has no prime factors other than 2 .

$(n, j)=\frac{1}{2}(j+1)(2 n+j)$ has at least one prime factor larger than 2 .

(a) If $j$ is even, $j+1$ is odd.

(b) If $j$ is odd, $2 n+j$ is odd.

Therefore, $(j),(n, j)$ has at least one odd factor larger than 1.

Such an odd factor is either a prime larger than 2, or contains a prime factor larger than 2 ; therefore $(n, j) \neq 2^{N}$.

Conjecture II. $(n, j)$ contains all numbers $\neq 2^{N}$.

Proof. (a) $(n, j)$ contains all odd numbers $>1$.

$(n, 1)=2 n+1$ (all odd numbers $>1)$.

(b) $(n, j)$ contains all numbers of the form $2^{N}\left(2 n+2^{N+1}-1\right)$.

Let $j=2^{N+1}-1$; hence $\frac{1}{2}(j+1)=2^{N}$.

Therefore $(n, j)=2^{N}\left(2 n+2^{N+1}-1\right)$.

$2 n+2^{N+1}-1$ covers all odd numbers equal to or larger than $2^{N+1}+1$.

(c) $(n, j)$ contains all numbers of the form $2^{N}\left(2^{N+1}-2 n+1\right)$.

Let $j=2 m$ (i.e., $j$ is even).

$(n, j)=(n, 2 m)=(2 m+1)(n+m)$;

if $n+m=2^{N}, m=2^{N}-n, 2 m+1=2^{N+1}-2 n+1$.

$(n, j) \Rightarrow 2^{N}\left(2^{N+1}-2 n+1\right)$.

Received May 26, 2005.

2000 Mathematics Subject Classification. Primary 11-XX.

(C)2005 Brown University

Reverts to public domain 28 years from publication 
$\left(2^{N+1}-2 n+1\right) \Rightarrow$ all odd numbers greater than 1 and $\leq 2^{N+1}-1$.

Thus we can construct all numbers of the form $2^{N} \times($ any odd integer $>1)$.

REMARKs. The history of this note is as follows. The senior author (LNC) visited his nine-year-old grandson Michael Britt, who, at that time, was in the fourth grade at the Montessori School in East Providence. Michael's teacher, Ms. Philips, had given her class a problem: to find numbers that are the result of sums of consecutive integers such as $1+2,2+3,3+4+5$, etc., or, in general, $n+(n+1)+\ldots+(n+j)$, where $n$ and $j$ are integers larger than zero.

Michael was very excited; he showed LNC a chart Lillie and he had made in which they plotted a matrix $n$ vs. $j$. They had verified that they could get all the numbers up to the mid-thirties, excluding $1,2,4,8,16$, and 32 . They also had circled 64 , in the upper, unexplored, portion of their chart; Michael told LNC they thought they could get all the numbers up to 64 , but not 64 , and larger except for "doubles of two" $\left(2^{N}\right)$. LNC posed Michael and Lillie's conjecture to his colleague DF. This note is the result. 